\title{
La Convención de la
}

\section{Unesco sobre protección}

y promoción de las expresiones culturales (20/10/2005), nuevo pilar de la gobernanza mundial en materia de cultura: una aproximación desde la economía

Luis Antonio Palma Martos 



\section{La Convención de la \\ Unesco sobre protección y promoción de las expresiones culturales (20/10/2005), nuevo pilar de la gobernanza mundial en materia de cultura: una aproximación desde la economía}

Luis Antonio Palma Martos*

Recibido: Agosto 2006

Aceptado: Septiembre 2006
* Universidad de Sevilla. Miembro de OIKOS 
"Los seres humanos son algo mejor que las criaturas ridiculas que son modeladas por la ideología contemporánea y por los intereses de poder a los que ésta sirve"

Noam Chomsky (2002, p. 46)

\section{Introducción}

Abordo en este trabajo una reflexión acerca de la controvertida relación entre cultura y mercado, tomando como referente la reciente "Convención sobre la protección y promoción de la diversidad de las expresiones culturales", aprobada por la Conferencia General de la Organización de las Naciones Unidas para la Educación, la Ciencia y la Cultura (UNESCO), en su $33^{\mathrm{a}}$ reunión celebrada en París, del 3 al 21 de Octubre de $2005^{1}$.

En el fondo de la cuestión se reproduce, ahora en el ámbito de las actividades, bienes y servicios culturales, la vieja discusión entre librecambio y proteccionismo, presente de forma recurrente en los debates de la ciencia económica. Las ventajas de la libertad comercial para el desarrollo de las naciones han sido puestas de manifiesto por los más distinguidos economistas a lo largo de historia de la economía y han inspirado políticas de enorme trascen- dencia para la prosperidad del planeta. Esta defensa de la libertad comercial es el objeto fundamental de organismos de carácter internacional como la Organización Mundial de Comercio (OMC), que en sucesivas rondas trata de ir eliminando por la vía de la negociación entre sus miembros, las barreras que limitan la libre circulación de bienes y servicios. Asimismo, la configuración de entidades supranacionales como la Unión Europea, Mercosur, etc... pone de manifiesto las ventajas de los mercados amplios y sin barreras y los efectos beneficiosos para todos de la colaboración en defensa de los principios del mercado libre y la competencia.

No obstante lo anterior, las políticas de corte proteccionista han tenido un relevante papel en diferentes épocas $y$, aún hoy, siguen presentes en muy diversos ámbitos, apoyadas en una variada gama de argumentos. Es el caso, por ejemplo, de la Política Agraria Común (PAC) en la Unión Europea, que trata de preservar un sector productivo, manifiestamente incapaz de competir en el escenario mundial, en este caso por razón de los elevados costes. Incluso en el seno de la propia Unión Europea se pone de manifiesto esta tensión entre libertad y protec-

1 La Convención (2005) define la diversidad cultural como: "Multiplicidad de formas en que se expresan las culturas de los grupos y sociedades. Estas expresiones se transmiten dentro y entre los grupos y las sociedades. Se manifiesta no sólo en las diversas formas en las que se expresa, enriquece y transmite el patrimonio cultural de la humanidad mediante la variedad de expresiones culturales, sino también a través de distintos modos de creación artística, producción, difusión, distribución y disfrute de las expresiones culturales, cualesquiera que sean los medios y tecnologías utilizados". 
ción a medida que se pretende extender el libre mercado desde los bienes a los servicios. Las dificultades para que la "directiva Bolkenstein" saliera adelante son una buena prueba de ello.

Si nos circunscribimos a la política económica cultural también nos encontramos con un viejo debate que acompaña a la ciencia económica desde su nacimiento (Lasuén et. al., 2005; pp. 315-325). Este debate, entre los economistas ortodoxos que consideraban que el objetivo básico de la humanidad era el progresivo aumento de la riqueza material y los Pundits estéticos de la Inglaterra victoriana ${ }^{2}$, que entendían que ese objetivo era el progreso hacia una mayor civilización, sólo alcanzable mediante la cultura, ha derivado en un cierto espacio de acuerdo. Se ha tratado, en definitiva, de encontrar razones que justifiquen, fortaleciéndola, la intervención creciente de los poderes públicos en materia de política cultural.

En el presente trabajo nos ocupamos de las actividades, bienes y servicios culturales ${ }^{3}$ y las políticas y medidas que pudieran llevarse a cabo para incentivar su creación, producción, difusión, distribución y acceso. Como telón de fondo, ya lo hemos apuntado, la Convención sobre la protección y promoción de la diversidad de las expresiones culturales, documento que defiende la adopción de medidas encaminadas a la preservación, salvaguardia y enriquecimiento de la diversidad de las expresiones culturales. Según reza en la propia Convención, "proteger" significa adoptar tales medidas ${ }^{4}$.

Para llegar a esta conclusión de carácter proteccionista se ha partido de una serie de definiciones que dan pie a unas reflexiones acerca de la diversidad cultural, para, a continuación, trazar los objetivos y principios rectores de la Convención. Asimismo, la Convención determina el ámbito de aplicación, los derechos y obligaciones de las partes y los órganos de la misma. En anexo al documento, se presenta el Procedimiento de conciliación, para dilucidar las controversias entre las partes.

Una vez concluida esta introducción, el trabajo va a estructurarse en cuatro partes adicionales. En la segunda, abordamos, a partir de los documentos de la UNESCO, una aproximación a la diversidad cultural como va-

2 Ver en Heilbroner (1999) el capítulo VII: "The Victorian World and the Underwold of Economics".

3 La Convención (2005) define las actividades, bienes y servicios culturales:

"Las actividades, los bienes y los servicios que, considerados desde el punto de vista de su calidad, utilización o finalidad específicas, encarnan o transmiten expresiones culturales independientemente del valor comercial que puedan tener. Las actividades culturales pueden constituir una finalidad por si, o contribuir a la producción de bienes y servicios culturales".

4 La Convención tiene su fundamento en un documento previo de la UNESCO (2002), la "Declaración universal de la UNESCO sobre la diversidad cultural". 
lor universal en múltiples ámbitos. A partir de esa consideración, nos detenemos a analizar la particular naturaleza de los bienes y servicios culturales, tomando como referencia tangencial los argumentos de la UNESCO, pero sobretodo incidiendo en aquellos procedentes del análisis económico. Esta excepcionalidad de los bienes y servicios culturales nos lleva en la parte cuarta a tratar una panorámica de las políticas culturales, sensibles a los elementos anteriormente apuntados. Volvemos a repasar los documentos de la UNESCO e incorporamos una somera visión de la política cultural de la U.E. en defensa de la diversidad cultural. El trabajo se cierra con un breve apartado de conclusiones y el preceptivo de referencias bibliográficas.

\section{La diversidad cultural como valor. Algunos elementos para la reflexión}

Parece conveniente antes de descender al debate entre la defensa de la cultura preservándola del mercado ${ }^{5} \mathrm{y}$ la necesidad de éste para la asignación eficiente de recursos escasos, también en el ámbito de la cultura, ofrecer un panorama de los principios que inspiran la Declaración Universal sobre la diversidad cultural y que han cristalizado en la Convención aprobada en el mes de Octubre de 2005. Siguiendo la estructura de la Declaración de 2002 los vamos a dividir en cuatro apartados.

5 Una primera y muy sugestiva reflexión entre cultura, en este caso arte, y mercado puede verse en la voz "Mercado"del divertido y enjundioso "Diccionario de las Artes" de Félix de Azua, publicado por Anagrama en su colección Argumentos. Manejo la segunda edición, de octubre de 2003.

También resulta de interés, para calibrar adecuadamente la perspectiva desde el mundo de los creadores, una conversación entre Antoni Tapies y Jose Angel Valente, recogida en el libro del último "Elogio del calígrafo. Ensayos sobre arte". Transcribimos, como muestra del debate acerca del papel del mercado en el ámbito artístico y cultural, un pasaje de la citada conversación (Valente, J.A.; 2002, pp. 9798):

"J.A.V.: El aspecto negativo sería la entrada de la obra de arte en el mercado. Está sujeta a factores relacionados con la propiedad y el dinero, a la circulación del capital y al estatuto simbólico con el que se asocia.

A.T.: Pero puede ser interesante considerar el mercado como una forma de selección. Porque sino lo haces así, ¿quién considerará la importancia de cada obra? ¿Unos funcionarios? ¿Unos políticos?

J.A.V.: lo negativo es que la obra está sujeta al mercado, que su valor dado muchas veces no tiene que ver con su calidad". 


\section{Identidad, diversidad y pluralismo}

Tres ideas fundamentales subyacen en este primer apartado: la consideración de la diversidad cultural como patrimonio de la humanidad, la relación entre diversidad y pluralismo culturales y la consideración de la diversidad cultural como factor de desarrollo. Detengámonos algo más en los contenidos de estas tres ideas.

El hecho de reconocer a la diversidad cultural como patrimonio de la humanidad procede de contemplarla como fuente de intercambios, de innovación y de creatividad. La Declaración (2002) observa que "la diversidad cultural es para el género humano tan necesaria como la diversidad biológica para los organismos vivos ". En el mismo sentido, la Convención (2005), afirma que la diversidad cultural es una característica esencial de la humanidad ${ }^{6}$.

Se entiende el pluralismo cultural como una interacción armoniosa y una voluntad de convivir de personas y grupos con identidades culturales a un tiempo plurales, variadas y dinámicas. En ese sentido, las políticas que favorecen la inclusión y la participación garantizan la cohesión social, la paz y la vitalidad de la sociedad civil. Así, entiende la Declaración (2002) que el pluralismo cultural constituye la respuesta política al hecho de la diversidad cultural. Giddens (1999, p. 161) afirma que es necesaria una perspectiva cosmopolita para una sociedad multicultural en un orden globalizador. Apunta al respecto: "Para promover una identidad cosmopolita han de cambiarse las leyes de nacionalidad y realizar un gran giro cultural. Una nación cosmopolita necesita valores con los que todos estén comprometidos y una identidad con la que los ciudadanos se sientan cómodos, pero también ha de aceptar la ambigüedad y la diversidad cultural" (Giddens, 1999, pp. 161-162).

Consideramos que la diversidad cultural se erige en factor de desarrollo al ampliar las posibilidades de elección de los ciudadanos. En todo caso, tanto la Declaración (2002) como la Convención (2005) hacen hincapié en una concepción de desarrollo que va más allá del mero crecimiento económico. Así, la Convención habla de desarrollo sostenible y la Declaración del desarrollo como medio de acceso a una existencia intelectual, afectiva, moral y espiritual satisfactoria.

6 No obstante, la existencia de la propia Convención pone de manifiesto el peligro que acecha a las diversas culturas -sobre todo a las minoritarias- que coexisten en el planeta. Bruckner (2003, p. 62) nos alerta: "Al reemplazar las grandes civilizaciones por la pobre universalidad de McDonald's, Disney, Coca-Cola, MTV, el hombre se convierte en una especie fisgona y apocada, idéntica en todas las latitudes". 


\section{Diversidad cultural y derechos humanos ${ }^{7}$}

En tres ámbitos diversos, aunque íntimamente relacionados, se traza la reflexión acerca de la diversidad cultural y los derechos humanos. En primer lugar, se afirma en la Declaración (2002) que los derechos humanos son garantes de la diversidad cultural. Se entiende que la defensa de la diversidad cultural es un imperativo ético, y no puede separarse del respeto a la dignidad del ser humano. Atención especial merecen las minorías y los pueblos autóctonos. En el mismo sentido, la Convención (2005) recoge como primer principio rector el del respeto a los derechos humanos y las libertades fundamentales (expresión, información y comunicación).

En segundo lugar, como parte integrante de los derechos humanos, los derechos culturales son el marco propicio de la diversidad cultural. Así, la Declaración (2002) afirma al respecto (art. 5):

"Toda persona debe, así, poder expresarse, crear y difundir sus obras en la lengua que desee y en particular en su lengua materna ${ }^{8}$; toda persona tiene derecho a una educación y una forma- ción de calidad que respete plenamente su identidad cultural; toda persona debe poder participar en la vida cultural que elija y ejercer sus propias prácticas culturales, dentro de los límites que impone el respeto de los derechos humanos y de las libertades fundamentales".

El tercer ámbito se centra en que la diversidad cultural sea accesible a todos. La Convención (2005) establece el principio rector de acceso equitativo. Se trata de que todas las culturas puedan expresarse y darse a conocer. La diversidad cultural se garantiza mediante la libertad de expresión, el pluralismo de los medios de comunicación, el multilingüismo, la igualdad de acceso a las expresiones artísticas, el saber científico y tecnológico y mediante la posibilidad de que todas las culturas estén presentes en los medios de expresión y difusión.

\section{Diversidad cultural y creatividad}

Para los propósitos de este trabajo este es el apartado de la Declaración (2002) que más nos interesa, puesto que incorpora el elemento creatividad, esencial para dinamizar proyectos de

7 Ver Vidal-Beneyto, J. (Ed.) (2006).

8 En todo caso, hay que asumir que la diversidad lingüística supone una barrera social que acaba por incorporar costes económicos. Gabriel Tortella lo ponía de manifiesto en un artículo en el diario El País (18 de Julio de 2006; p. 13), al señalar las difícultades de la Unión Europea para la consecución de un verdadero mercado único: “...la movilidad de la mano de obra y de los servicios se ve obstaculizada, más aún que por la legislación, por la fragmentación lingüistica y cultural". Señala Tortella que el coste de las barreras lingüísticas (aunque las estimaciones puedan resultar discutibles) oscilaría entre uno y dos puntos del crecimiento del Producto Interior Bruto. 
naturaleza cultural pero no sólo, como apuntaremos más adelante. $\mathrm{Al}$ mismo tiempo que se defiende al patrimonio cultural en todas sus formas y se determina su preservación y valorización a fin de que pueda nutrir la creatividad, la Declaración (2002) traza en el artículo 8 los argumentos esenciales de la excepción cultural, al afirmar que los bienes y servicios culturales son mercancías distintas de las demás. En el próximo epígrafe profundizaremos esta argumentación.

En un tono similar se expresa la Convención (2005) cuando afirma que las actividades, los bienes y servicios culturales son de índole a la vez económica y cultural, porque son portadores de identidades, valores y significados, y por consiguiente no deben tratarse cono si sólo tuviesen un valor comercial.

En este mismo apartado, la Declaración (2002) apunta a las políticas culturales como catalizadoras de la creatividad, al garantizar la libre circulación de ideas y obras, creando las condiciones propicias para la producción y difusión de bienes y servicios culturales diversificados, gracias a industrias culturales con capacidad de actuar tanto en el plano local como global. En este sentido, afirma: "Cada Estado debe, respetando sus obligaciones internacionales, definir su política cultural y aplicarla, utilizando para ello los medios de acción que juzgue más adecuados, ya se trate de apoyos concretos o de marcos reglamentarios apropiados".

\section{Diversidad cultural y solidaridad internacional}

En este cuarto apartado, la Declaración (2002) proclama la necesidad de reforzar las capacidades de creación y difusión a escala mundial. Una línea en esta dirección sería la de reforzar la cooperación y solidaridad internacionales, dados los perceptibles desequilibrios que se producen en los intercambios de bienes culturales en el mercado internacional. Se trataría, como objetivo, de que todos los países, y en particular los países en vías de desarrollo, pudieran disponer de industrias culturales competitivas, tanto a escala nacional como internacional. Con relación a estos objetivos, la Convención (2005) recoge los principios rectores de solidaridad y cooperación internacionales y de complementariedad de los aspectos económicos y culturales del desarrollo.

Asimismo, la Declaración (2002) incide en el establecimiento de relaciones de asociación entre el sector público, el privado y la sociedad civil. A este respecto, se desliza una crítica a las capacidades del mercado: "Las fuerzas del mercado por sí solas no pueden garantizar la preservación y promoción de la diversidad cultural, condición de un desarrollo humano sostenible. Desde este punto de vista, conviene fortalecer la función primordial de las políticas públicas, en asociación con el sector privado y la sociedad civil". A partir de esta reflexión 
se justifica una intervención pública, que quedará perfilada en el subsiguiente "Plan de Acción".

\section{La particular naturaleza de los bienes y servicios culturales. Una aproximación desde el análisis económico}

En el apartado anterior nos hemos detenido en plantear una amplia reflexión acerca de los valores que la diversidad cultural aporta a la humanidad. Considero que los argumentos esbozados constituyen un buen punto de partida para la defensa de esta diversidad cultural a través de las medidas políticas necesarias. A ellas nos referiremos en el próximo apartado.

No obstante, antes de abordar la acción política, me gustaría dedicar un espacio a esbozar argumentos para la defensa de la "excepcionalidad cultural", a partir, precisamente, de las características de las actividades, bienes y servicios culturales, que los hacen diferentes, excepcionales, al resto de las mercancías, lo que propicia una intervención pública por motivos de tono menos elevado a los expuestos en el apartado anterior y vinculados, fundamentalmente, al análisis económico como disciplina.

\subsection{Los argumentos de la UNESCO}

El artículo 8 de la Declaración (2002) es muy explícito. Su título reza: "Los bienes y servicios culturales, mercancías distintas de las demás". A partir de este título-afirmación desgrana una serie de argumentos:

"Frente a los cambios económicos y tecnológicos actuales, que abren vastas perspectivas para la creación y la innovación, se debe prestar una atención particular a la diversidad de la oferta creativa, a la justa consideración de los derechos de los autores y de los artistas así como al carácter específico de los bienes y servicios culturales que en la medida que son portadores de identidad, de valores y sentido, no deben ser considerados como mercancías o bienes de consumo como los demás".

La Convención (2005) es menos precisa, aunque a lo largo de la misma se pueden encontrar, reelaborados, los argumentos utilizados en el artículo 8 de la Declaración (2002). Así, en su preámbulo se recogen tres párrafos en sintonía con el citado artículo:

"Reconociendo la importancia de los derechos de propiedad intelectual para sostener a quienes participan en la creatividad cultural,

Persuadida de que las actividades, los bienes y servicios culturales son de indole a la vez económico y cultural, porque son portadores de identidades, valores y significados, y por consiguiente no deben tratarse como si sólo tuviesen un valor comercial,

Observando que los procesos de mundialización, facilitados por la evolución rápida de las tecnologías de la información y la comunicación, pese a que crean condiciones inéditas para que se intensifique la interacción entre las culturas, constituyen también un desafio 
para la diversidad cultural ${ }^{9}$, especialmente en lo que respecta a los riesgos de desequilibrio entre países ricos y pobres..."

A mayor abundamiento la Convención (2005) incorpora entre sus objetivos el de "reconocer la índole específica de las actividades, los bienes y servicios culturales en su calidad de portadores de identidad, valores y significado". También podríamos apuntar el principio rector de complementariedad de los aspectos económicos y culturales del desarro1lo, habida cuenta de la consideración de la cultura como uno de los principales motores del mismo ${ }^{10}$.

\subsection{Los rasgos diferenciales de los bienes y servicios culturales desde el análisis económico}

La reflexión que vamos a llevar a cabo en este apartado va a estar fundamentada en el análisis microeconómico convencional (Lasuén et al., 2005; cap. $\mathrm{X})$. La concepción de economía de la cultura subyacente en este enfoque -la más extendida en el mundo académico occidental-comprende a las actividades artísticas (teatro, música, ópera, danza, artes visuales, artesanía, lite- ratura, artes populares y comunitarias) y a las de entretenimiento y ocio (películas, radio y televisión, edición y publicación). Quizá quepa señalar que la batalla en defensa de la excepcionalidad cultural y la necesidad de llevar a cabo políticas de índole proteccionista está más centrada en estas últimas actividades, presentes en un grado muy superior en los mercados internacionales.

Vamos a abordar la caracterización de los bienes y servicios culturales desde el análisis económico deteniéndonos en las dos perspectivas clásicas: la que toma en consideración cuestiones de eficiencia y aquella que fija su atención en los aspectos de equidad.

\subsubsection{La caracterización de los}

bienes y servicios culturales desde la eficiencia

Partamos de una carencia de principio. No existe una definición adecuada de lo que son bienes y servicios culturales y, desde luego, tampoco de cultura (Lasuén et al., 2005, p. 57). Adaptando la definición esbozada al inicio de este apartado se pueden destacar algunas características, que nosotros vamos a cifrar en cuatro ámbitos.

En primer lugar, la mayor parte de los bienes culturales podrían calificarse de servicios. La razón de conside-

\footnotetext{
9 Ver Acheson, K. (2005).

10 El análisis del vínculo entre cultura y crecimiento económico, tomando como puente entre ambos el fomento de la creatividad y su impacto en la capacidad innovadora, está comenzando a ser explorado desde perspectivas diversas. Pueden verse al respecto, Lasuén, J. R. y Aranzadi, J. (2002); Lasuén, J. R.; García, M. J. y Zofío, J. L. (2005) y Palma, L. (2006).
} 
rar servicios a lo que, en principio, son objetos - un cuadro o un libro- es que su valor viene determinado casi exclusivamente por su contenido, que es trabajo conceptual o intelectual. El uso de estos bienes tiene rasgos similares al de los bienes públicos, pues el conocimiento que incorporan es acumulable y en algunos casos también su continente; muchos de ellos son asimismo de gran durabilidad. Otro rasgo que los aproxima a los bienes públicos es la inexcluibilidad en su uso. Muchas personas pueden disfrutar de ellos al mismo tiempo sin que pierdan por ello su valor, lo que hace socialmente indeseable limitar su uso.

En segundo lugar, muchos bienes culturales y artísticos tienen un valor que aumenta con el tiempo. Este hecho, unido a la posible durabilidad del bien los hace susceptibles de convertirse en activos ${ }^{11}$ que pueden intercambiarse en mercados específicos.

En tercer lugar, el consumo de bienes artísticos y culturales presenta adictividad, contraviniendo la ley de la utilidad marginal decreciente expuesta por Alfred Marshall. Este justificó esta adictividad como la excepción de la regla, debido a la intensificación del gusto por el arte, adquirido a partir de un consumo repetido del mismo. Gary Becker buscó una explicación alternativa a la observada adictividad -que Lasuén et al. (2005, p. 58) consideran más satisfactoria-según la cual lo que varía con el consumo de bienes y ser- vicios culturales y artísticos no son los gustos sino la capacidad y la habilidad intelectual de los consumidores para apreciar la calidad de los bienes, que aumenta con la experiencia, lo que Becker denomina capital de consumo.

Por último, se pueden caracterizar a estos bienes como de mérito, lo que podría conllevar que las preferencias individuales y sociales con relación a estos bienes difirieran. Sería el caso, por ejemplo, de la defensa del cine español por parte del Ministerio de Cultura, al objeto de salvaguardar ciertos valores. El hecho mismo de la intervención nos señala que los individuos no estarían, por sí mismos, dispuestos a llevar a cabo el consumo de cine español en la cantidad que la sociedad -cuyas preferencias se revelan a través de un proceso político- considera satisfactoria. Vamos a profundizar en esta característica al abordar el análisis desde la perspectiva de la equidad.

\subsubsection{La caracterización de los}

bienes y servicios culturales desde la equidad

Para llegar a la conclusión de que los bienes y servicios culturales, o al menos una buena parte de ellos, se deben asignar a través de un proceso político y no a través del mercado, debe caracterizarse a aquellos como bienes de mérito. Lasuén et al. (2005, p. 50) siguen a Musgrave al señalar que " $\mathrm{el}$ bien de mérito es un bien que surge debido a una preferencia comunita-

11 Para una aproximación a los mercados del arte desde la perspectiva de la Economía de la Cultura ver Palma Martos, L. (2004). 
ria, social, no individual, al que tienen derecho a acceder todos los ciudadanos si lo desean, normalmente de forma gratuita. Es un bien que una comunidad cree que deben poseer todos sus ciudadanos aunque algunos de ellos no lo deseen ${ }^{12}$ ".

Posiblemente, y así lo destaca Musgrave, los bienes artísticos y culturales estarían más cerca de los bienes de mérito que de los colectivos. Como ejemplos de bienes de mérito Musgrave señaló: la preocupación por el mantenimiento de los lugares históricos, el respeto por las fiestas nacionales, el respeto por el medio ambiente y el interés por el estudio y la cultura.

Los bienes de mérito se caracterizan por resultar de un "proceso histórico de sedimentación de preferencias comunitarias acerca de lo que es fundamentalmente deseable o indeseable para la comunidad" (Lasuén et al., 2005, pp. 60-61). Este proceso histórico lleva a los ciudadanos a aceptar la conveniencia de satisfacer esas preferencias comunitarias y contribuir a la financiación de las mismas, incluso en el caso de que estas preferencias comunitarias fueran diferentes de las del propio individuo.

\subsection{La internacionalización del comercio de bienes y servicios culturales}

El mercado de bienes y servicios culturales es posiblemente uno de los más internacionalizados. Ante esta realidad cabría hacerse la pregunta de qué determina los patrones de comercio de este tipo de bienes.

Schulze (2005) aborda diversos aspectos del comercio internacional de los bienes culturales que nos parecen de interés. Toma el carácter adictivo de la demanda de este tipo de bienes que ya hemos señalado para introducir el concepto - originario de Beckerde capital de consumo. Este capital de consumo tendría dos componentes, uno personal, constituido por el consumo privado y otras experiencias de consumo relevantes, y otro social, que procede de la influencia de los demás, ya sean iguales o personas relevantes, influyentes en la toma de decisiones de consumo. Schulze (2005) señala dos implicaciones del concepto de adicción positiva en el contexto internacional. En primer lugar, las personas conceden menos valor a los bienes culturales extranjeros debido a la falta

12 Lasuén et al. (2005, pp. 59-61) incorporan una interesante discusión de tono metodológico acerca del tratamiento debido o indebido de los bienes y servicios culturales por parte de la economía neoclásica al confundir los bienes meritorios con los colectivos. Estos últimos serían de preferencia individual y beneficiarían directamente a quienes los consumieran e indirectamente a los demás. 
de acumulación de capital de consumo personal y subdesarrollo del social. En este sentido, encontraríamos que el comercio bilateral de bienes culturales será mayor entre países cuyas culturas (podríamos apuntar la lengua) están más próximas. También pudiera suceder que la acumulación de capital de consumo cultural fuera asimétrica ${ }^{13}$. En segundo lugar, Schulze señala un fenómeno de histéresis en el comercio internacional de estos bienes, pues éste depende de la proximidad cultural y además el comercio actual depende del pasado.

Desde la oferta, Schulze (2005) pone de manifiesto la heterogeneidad del concepto bien o servicio cultural, clasificando a estos bienes en dos categorías: bienes únicos y bienes reproducibles. En el primer caso, podemos pensar en un cuadro, se caracterizan por que se producen en un único paso creativo. Suelen ser duraderos y valiosos y generan un mercado secundario entre consumidores actuales y futuros, que suele dominar el mercado primario, dada la baja sustituibilidad entre los objetos de arte ya reconocidos y los nuevos.

El volumen de transacciones en este mercado se ve favorecido por el nivel de renta (son bienes de lujo); por la proximidad cultural y por la pertenencia de los agentes al mismo bloque comercial.
Los bienes reproducibles (libros, música grabada...) requieren dos pasos, un primer paso que supone la creación y un segundo, para llevar a cabo la reproducción, que tiene lugar con fuertes economías de escala y de alcance. También se dan economías de escala sectoriales, ya sea a nivel local, nacional o internacional. La proximidad cultural es también crucial en el comercio de este tipo de bienes ${ }^{14}$.

\section{La diversidad cultural y las políticas públicas}

En el apartado anterior hemos abordado un conjunto de argumentos que hacen de los bienes y servicios culturales unas "mercancias distintas de las demás” y por ello debían sustraerse en su creación, producción y comercialización a las leyes del mercado.

Desde la eficiencia habría que garantizar la existencia de esos bienes -considerados de mérito- puesto que la demanda podría no existir por falta de conocimiento o por falta de educación respecto al consumo de estos bienes. Desde la equidad habría que garantizar el acceso a estos bienes de todas las capas sociales. La excepción cultural queda reforzada al reconocer la propia diversidad cultural como un valor en sí misma. Por ello, es necesario el diseño de políticas que la preserven de

13 Este hecho puede observarse en la diversa penetración que tiene el cine norteamericano en Europa frente al cine europeo en los Estados Unidos.

14 Estos elementos pueden reconocerse en la supremacía a escala internacional del cine estadounidense. 
los procesos homogeneizadores, que se consideran desatienden los valores culturales, primando los mercantiles, en una espiral de nefastas consecuencias para la propia naturaleza humana $\mathrm{y}, \mathrm{a}$ largo plazo, para las mismas bases económicas en las que la vida del hombre se asienta.

En este apartado vamos a repasar las políticas planteadas con este objetivo en la Convención de la UNESCO (2005) y la posición de la Unión Europea sobre la defensa del principio de la diversidad cultural.

\subsection{Las políticas culturales en la convención de la UNESCO (2005)}

El artículo 5 de la Convención que recoge la norma general relativa a los derechos y obligaciones de las partes, integrado en la parte IV de la Convención, reconoce el derecho soberano de éstas a formular y aplicar sus políticas culturales y a adoptar medidas para proteger y promover la diversidad de las expresiones culturales, así como a reforzar la cooperación internacional para lograr los objetivos de la Convención. Se busca asimismo la coherencia entre las políticas nacionales y las disposiciones de la Convención.
El artículo 6, bajo el título "Derechos de las partes en el plano nacional" recoge un listado de ocho posibles políticas y medidas culturales que previamente han sido definidas genéricamente en el artículo $4.6^{15}$. Repasemos brevemente esta tipología de medidas:

- Medidas reglamentarias encaminadas a la protección y promoción de la diversidad de las expresiones culturales.

- Medidas que brinden oportunidades a las actividades y los bienes y servicios culturales nacionales para la creación, producción, distribución, difusión y disfrute, comprendidas las disposiciones relativas a la lengua utilizada.

- Medias encaminadas a proporcionar a las industrias culturales independientes nacionales un acceso efectivo a los medios de producción, difusión y distribución.

- Medidas destinadas a conceder asistencia financiera pública.

- Medidas dirigidas a alentar organizaciones sin fines de lucro, así como a entidades públicas y privadas, artistas y otros profesionales de la cultura, a impulsar y promover el libre intercambio y circulación de ideas, expresiones, actividades, bienes y servicios culturales y a estimular en sus actividades el espíritu creativo y el espíri-

15 El citado artículo 4 párrafo 6 dice que "Las " políticas y medidas culturales" se refieren a las políticas y medidas relativas a la cultura, ya sean éstas locales, nacionales, regionales o internacionales, que están centradas en la cultura como tal, o cuya finalidad es ejercer un efecto directo en las expresiones culturales de las personas, grupos o sociedades, en particular la creación, producción, difusión y distribución de las actividades y los bienes y servicios culturales y el acceso a ellos". 
tu de empresa.

- Medidas destinadas a crear y apoyar las instituciones de servicio público pertinentes.

- Medidas encaminadas a respaldar y apoyar a los artistas y demás personas que participan en la creación de expresiones culturales.

- Medidas destinadas a promover la diversidad de los medios de comunicación social, comprendida la promoción del servicio público de radiodifusión.

A este listado del artículo 6 habría que añadir dos conjuntos de medidas recogidos en los artículos 7 y 8 . En el 7, se insta a las partes (gobiernos nacionales ), bajo el rótulo "Medidas para promover las expresiones culturales", a crear un entorno favorable a la creación, producción, difusión y distribución de las expresiones culturales autóctonas. Se pone un énfasis especial en las circunstancias y necesidades especiales de mujeres, minorías y pueblos autóctonos. Asimismo se considera muy relevante propiciar el acceso a las diversidades culturales ya sean internas como del resto del mundo.

El artículo 8 faculta a las partes a llevar a cabo medidas protectoras de las expresiones culturales en su territorio en el caso de que corran el riesgo de extinguirse, sufran una grave amenaza o requieran una medida urgente de salvaguarda.

En el resto del articulado de esta IV parte se sugieren otra serie de posibles medidas encaminadas a promover la educación y sensibilización del público en esta materia (Artículo 10); fomentar la participación de la sociedad civil (Artículo 11), promover la cooperación internacional (Artículo 12), integrar la cultura en el desarrollo sostenible (Artículo 13); y apoyar la cooperación para el desarrollo (Artículos 14, 15, 16 y 17). Asimismo se crea por el artículo 18 el Fondo Internacional para la Diversidad Cultural.

Vemos, pues, que la Convención da carta blanca a los gobiernos nacionales en lo que se refiere a políticas culturales, primando en todo momento los aspectos culturales frente a los económicos. Debe entenderse en este sentido que defender la diversidad cultural significa, y así lo ha asumido la UNESCO, que la asignación de los recursos en este ámbito se debe realizar mediante el proceso político, limitando de forma sustancial el papel del mercado. En todo caso, la Convención de la UNESCO (2005) no hace más que reforzar una línea ya presente, por ejemplo, en el Tratado de Roma, cuyo artículo 36 recogía el derecho de los Estados miembros de la Unión Europea a proteger el patrimonio cultural imponiendo restricciones a la exportación de obras de arte, siendo muy libres para definir lo que consideraban patrimonio cultural. A lo dispuesto en este artículo cabría añadir un conjunto de medidas que suponen una clara intervención de los gobiernos en el comercio internacional de bienes culturales: la regulación del IVA; el "droit de suite" concedido a los artistas, subvenciones directas o indirectas vía deducciones fiscales, o la habitual in- 
tervención en el sector cinematográfi$\mathrm{co}^{16}$.

No obstante lo anterior, Schulze (2005) afirma que en qué grado distorsionan realmente al comercio internacional de bienes y servicios culturales las intervenciones del gobierno es una cuestión empírica que hasta el momento no ha sido resuelta.

\subsection{La Unión Europea y la defensa del principio de diversidad cultural}

La Convención adoptada por la UNESCO el 20 de Octubre de 2005 fue negociada de manera conjunta por la Comisión Europea, en nombre de la Comunidad, y por la Presidencia del Consejo, en nombre de los Estados miembros. La Comisión Europea (2005a) considera que la Convención supone una primicia histórica en las relaciones internacionales al consagrar un consenso, inédito hasta el momento, en la comunidad internacional en torno a un conjunto de principios rectores y de conceptos vinculados a la diversidad cultural y constituir la base de un nuevo pilar en la gobernanza mundial en materia de cultura.

A juicio de la Comisión Europea (2005a) la Convención contribuye a reconocer el papel y la legitimidad de las políticas públicas para la protección y la promoción de la diversidad cultural; también reconoce la importancia de la cooperación internacional, sobre todo para hacer frente a situa- ciones de vulnerabilidad cultural en los países en desarrollo. Asimismo, la Convención define una adecuada articulación con otros instrumentos al objeto de aplicarla de manera eficaz, amén de constituir una nueva plataforma para abordar la cultura en el contexto más amplio del desarrollo sostenible.

Debemos señalar que la conservación y el fomento de la diversidad cultural figuran entre los principios fundadores de la Comunidad y están inscritos en el artículo 151 del Tratado (antes 128) y en el artículo 22 de la Carta de Derechos Fundamentales de la Unión Europea. Para su aplicación, el principal instrumento de la política europea es el programa "Cultura 2000 " cuyo objetivo es el desarrollo de un espacio cultural común mediante el apoyo a proyectos artísticos y culturales de dimensión europea en su concepción, organización y realización (Comisión Europea, 2005b). La vigencia del programa alcanza hasta el 2006 y se ha visto completado por el programa de actuación comunitario para la promoción de organismos culturales europeos en el período 2004-2006. El futuro vendrá marcado por el programa "Cultura 2007" que retomará y completará gran parte de las actividades de los citados programas. Asimismo, y con vistas a promover y proteger los intercambios y la diversidad cultural en la Unión, la Comisión propuso declarar 2008 como "Año Europeo del Diálogo Intercultural”.

16 Ver Fernández Blanco, V. y Prieto Rodríguez, J. (2006). 
Hemos apuntado anteriormente que la Comisión Europea (2005a) entiende que la Convención adoptada por la UNESCO constituye un nuevo pilar de la gobernanza mundial. Y esto es así porque permite colmar un vacío jurídico al establecer un conjunto de derechos y obligaciones, tanto a escala nacional como internacional con vistas a la protección y promoción de la diversidad cultural. Debía, en este sentido, desempeñar un papel comparable -y tener el mismo nivel normativo- al que desempeñan en sus ámbitos respectivos las convenciones de la Organización Mundial de la Propiedad Intelectual (OMPI), los Acuerdos de la Organización Mundial de Comercio (OMC) y de la Organización Mundial de la Salud (OMS).

El objetivo general de la Convención es tener en cuenta la diversidad cultural a la hora de desarrollar políticas públicas y garantizar que las políticas en materia de cultura contribuyan al acceso igualitario, tanto a las culturas locales como a las demás culturas del mundo. A partir de esta premisa, la Convención de la UNESCO es, desde la óptica de la Comisión Europea, una transposición al ámbito internacional de los principios comunitarios y en particular del, ya citado, artículo 151, en el que se establece que la Comunidad tendrá en cuenta los aspectos culturales en su actuación en virtud de otras disposiciones del Tratado (Art. 151.4).

Nos gustaría señalar, por último, que la Comisión Europea (2005a) entiende que la Convención no pone en tela de juicio los compromisos suscritos en la OMC. No tiene por objeto ni efecto la exclusión de los bienes y servicios culturales de los acuerdos de la OMC. Es más, la Convención reconoce, como hemos visto, la particularidad de los bienes y servicios culturales y legitima las políticas culturales tanto internas como internacionales. Habría que añadir al respecto que la Comunidad y sus Estados miembros, mantienen una posición clara en la OMC en cuanto a los servicios culturales y audiovisuales, que consiste en preservar su capacidad para mantener y elaborar políticas en dichos ámbitos.

\section{Conclusiones}

En el ya viejo debate entre cultura y mercado, la Convención sobre la protección y promoción de la diversidad de las expresiones culturales, adoptada el 20 de Octubre de 2005 por la UNESCO, supone una victoria de los planteamientos estéticos frente a los económicos. Así por lo menos parece a primera vista.

No obstante, hay que considerar que ese viejo debate ha ido buscando $\mathrm{y}$, finalmente, encontrando espacios de consenso, argumentos con los que los economistas han contribuido a justificar y fortalecer las políticas en defensa de una cierta excepcionalidad cultural. Quizá el argumento de mayor peso esgrimido ha sido el de considerar a los bienes y servicios culturales como bienes de mérito. Este argumento, junto a otros que hemos tenido ocasión de analizar, tanto en su ver- 
tiente teórica como de plasmación política, constituyen un cuerpo doctrinal que da carta de naturaleza a una variada gama de intervenciones públicas.

Como bien apunta la Comisión Europea, la Convención se erige, en el ámbito de la cultura, en un nuevo pilar de la gobernanza mundial; y ese pilar cuenta con este bagaje doctrinal para reforzar su presencia en un entorno en el que las fuerzas económicas barren -acaso sin pretenderlo conscientemente- las diversas manifestaciones culturales, en un proceso homogeneizador que supone un riesgo para la humanidad, tanto en términos de riqueza patrimonial como económica, si aceptamos que la diversidad creativa es una fuente de prosperidad.

\section{Bibliografía}

Acheson, K. (2005) “La globalización”, en Towse, R. (2005), pp. 391-401.

Azúa, Félix de (2003) Diccionario de las Artes, Anagrama. Colección Argumentos, Barcelona.

Bruckner, P. (2003) Miseria de la prosperidad. La religión del mercado y sus enemigos, Tusquets Editores, Barcelona.

Chomsky, N. (2002) "Los mercados y la « «sustancia de la sociedad»", en García Albea, J. E. et al. (2002) (Coord.), pp. 21-46.

Comisión Europea (2005a) “Adopción de una Convención sobre la diversidad cultural en la UNESCO", MEMO/05/ 387 (21/10/2005). http://europa.eu.int/ rapid/pressReleasesAction.doc. Consultado el 4/4/2006.

Comisión Europea (2005b) "Informe general sobre la actividad de la Unión
Europea.2005". http://europa.eu.int/ abc/doc/off/rg/es/2005/rg72.htm. Consultado el 4/4/2006.

Fernández Blanco, V. y Prieto Rodríguez, J. (2006) "El mercado del cine en España, Cuadernos de Economía de la Cultura, No 4-5, pp. 7-29.

García Albea, J. E.; Catalá, N. y Díez Calzada, J. A. (2002) (Coord.) Los límites de la globalización, Ariel Practicum, Barcelona.

Giddens, A. (1999) La tercera vía. La renovación de la socialdemocracia, Taurus, Madrid.

Heilbroner, R. L. (1999) The worldly Fhilosophers. The lives, times and ideas of the great economic thinkers, $7^{\mathrm{a}}$ Edición revisada. Touchstone, Nueva York.

Lasuén, J. R. y Aranzadi, J. (2002) El crecimiento económico y las artes, Sociedad General de Autores y Editores. Fundación Autor. Madrid.

Lasuén, J. R.; García, M. I. Y Zofío, J. L. (2005) Cultura y Economía, Fundación Autor. Madrid.

Palma Martos, L. (2006) “Cultura y crecimiento económico. Un enfoque exploratorio a propósito del Plan Estratégico de la Cultura en Andalucía (PECA)", Cuadernos de Economía de la Cultura, No $4-5$, pp. 117-123.

Palma Martos, L. (2004) "Mercado del Arte y Economía de la Cultura", Cuadernos de Economía de la Cultura, $\mathrm{N}^{\mathrm{O}}$ 3, pp. 15-26.

Schulze, Günther G. (2005) "El comercio internacional”, en Towse R. (2005), pp. 145-155.

Throsby, D. (1994) "The production and consumption of the arts: view of cultural Economics", Journal of Economic Literature, Vol XXXII, March pp. 129.

Tortella, G. (2006) "Tan largo me lo fiáis...", Diario El País (18 de julio) p. 13. 
Towse, R. (2005) Manual de Economía de la Cultura, Fundación Autor, Madrid. UNESCO (2005) “Convención sobre la protección y promoción de la diversidad de las expresiones culturales", París.

UNESCO (2002) "Declaración Universal de la UNESCO sobre la diversidad cultural", París.
Valente, José Ángel (2002) Elogio del caligrafo. Ensayos sobre arte, Galaxia Gutenberg. Círculo de Lectores, Barcelona.

Vidal-Beneyto, J. (Ed.) (2006) Derechos humanos y diversidad cultural. Globalización de culturas y derechos humanos, Icaria Antrazyt, Barcelona. 